\title{
Análise da cadeia de produção de verduras em Ribeirão Preto, SP
}

\author{
Analysis of the vegetable productive chain \\ in Ribeirão Preto, SP
}

\section{Osvaldo M. Takayanagui', Divani M. Capuano², Carlos A.D. Oliveira ${ }^{3}$, Alzira M.M. Bergamini², Madalena H.T. Okino², Ana A.M.C. Castro e Silva ${ }^{3}$, Maria A. Oliveira², Eliana G.A. Ribeiro ${ }^{2}$ e Angela M.M. Takayanagui ${ }^{4}$}

\begin{abstract}
RESUMO
Com o objetivo de avaliar o risco cumulativo de contaminação de hortaliças, investigou-se 45 cadeias produtoras. Foi detectada a presença de coliformes a $45^{\circ} \mathrm{C}$, Salmonella e/ou parasitas em $69 \%$ delas, em todas as etapas de produção. Ressalta-se a necessidade de se intensificar o controle de qualidade ao longo da cadeia produtiva.
\end{abstract}

Palavras-chaves: Hortaliças. Alface. Coliformes a $45^{\circ} \mathrm{C}$. Salmonella. Parasitas.

\begin{abstract}
With the aim of assessing the cumulative risk of lettuce contamination, 45 production chains were investigated. The presence of thermotolerant coliforms, Salmonella and/or parasites was detected in $69 \%$ of these, in all steps of the production chain. Quality control in all steps of the lettuce production process should be intensified.
\end{abstract}

Key-words: Vegetables. Lettuce. Thermotolerant coliforms. Salmonella. Parasites.

O consumo de verduras cruas constitui importante meio de transmissão de várias doenças infecciosas ${ }^{4}$. Embora tenham sido conduzidos em épocas diferentes, estudos realizados em nosso município avaliando as condições higiênico-sanitárias de hortaliças nas hortas ${ }^{8}$ e no comércio ${ }^{9}$ demonstraram que a frequiência de contaminação nos dois extremos da cadeia de produção de hortaliças foi altamente discrepante, com $20 \%$ e $58,1 \%$, respectivamente. Possivelmente, esses resultados foram decorrentes do risco acumulado de contaminação nas sucessivas etapas do processo produtivo, incluindo o transporte e a manipulação de alimentos. Procuramos neste estudo avaliar o eventual risco cumulativo de contaminação de hortaliças nas sucessivas etapas de produção, desde o canteiro das hortas até o ponto de venda à população.

Entre julho de 1998 e novembro de 1999, foram colhidas amostras de 45 cadeias produtivas de hortaliças, incluindo hortas (água de irrigação, verduras no canteiro, água do tanque de lavagem e verduras após a lavagem) e os respectivos pontos de venda final ao consumidor (supermercados, quitandas, mercearias e feiras-livres) dos quais foram obtidas amostras de verduras. Procurou-se assegurar o vínculo entre a horta e o ponto de venda, confirmando o elo da cadeia de produção, excluindo os casos duvidosos.

Amostras da água de irrigação e da utilizada na lavagem das verduras foram recolhidas em frascos estéreis de $250 \mathrm{ml}$ para análise microbiológica. Para a pesquisa parasitológica, foram obtidas amostras de 2 litros da água de irrigação, 2 litros da água de superfície e 1 litro do fundo do tanque de lavagem. Foi também realizada a coleta aleatória de 2 pés de verduras de folha do canteiro, preferencialmente a alface (Lactuca sativa) e, após lavagem, acondicionando-as individualmente em sacos plásticos de primeiro uso, sem contato manual. Todas as amostras foram obtidas e encaminhadas no mesmo dia ao Instituto Adolfo Lutz de Ribeirão Preto, para as análises laboratoriais.

\footnotetext{
1. Departamento de Neurologia da Faculdade de Medicina de Ribeirão Preto da Universidade de São Paulo, São Paulo, SP. 2. Instituto Adolfo Lutz - Laboratório I de Ribeirão Preto, Ribeirão Preto, SP. 3. Secretaria Municipal da Saúde de Ribeirão Preto, Ribeirão Preto, SP. 4. Disciplina de Saúde Pública da Escola de Enfermagem de Ribeirão Preto da Universidade de São Paulo, Ribeirão Preto, SP.

Apoio financeiro: Conselho Nacional de Desenvolvimento Científico e Tecnológico (CNPq) - OMT (Proc. \#300937/2003-2).

Endereço para correspondência: Dr. Osvaldo M. Takayanagui. Dept ${ }^{\circ}$ de Neurologia/FMRP/USP. Av. Bandeirantes 3900, 14048-900 Ribeirão Preto, SP.

Tel: 5516 3602-2472; Fax: 55 16-3602-2548

e-mail: otakay@rnp.fmrp.usp.br

Recebido para publicação em 9/5/2005

Aceito em 16/12/2005
} 
A análise microbiológica foi fundamentada na determinação do número mais provável (NMP/g) de coliformes a $45^{\circ} \mathrm{C}$ e na pesquisa de Salmonella sp, segundo o APHA $^{3}$. A legislação brasileira em vigor ${ }^{1}$ exige ausência de Salmonella sp em $25 \mathrm{~g}$ nesta classe de alimento. Efetuamos a contagem de coliformes a $45^{\circ} \mathrm{C}$, pois estes indicam a ocorrência de contaminação fecal em alguma etapa da cadeia de produção de verduras. A análise parasitológica das hortaliças foi realizada segundo Marzochi ${ }^{7}$ com modificações, de acordo com Takayanagui et al ${ }^{8}$. As águas de irrigação e dos tanques de lavagem foram deixadas em repouso em cálices cônicos por 24 horas, após filtragem em gaze de 8 dobras. Os sedimentos obtidos foram analisados ao microscópio por exame direto e após centrífugo-flutuação em sulfato de zinco $(d=1.180)$. Outra parte do sedimento foi submetida à técnica de concentração pelo formol-éter ${ }^{6}$ para a pesquisa de oocistos de coccídeos.

A análise microbiológica da água de irrigação foi realizada segundo técnica recomendada pela $\mathrm{APHA}^{2}$ e teve como indicador de contaminação fecal o NMP de coliformes a $45^{\circ} \mathrm{C} /$ $100 \mathrm{ml}$, segundo legislação em vigor ${ }^{5}$. A análise estatística foi baseada no teste de McNemar para amostras correlacionadas, adotando $\mathrm{p} \leq 0,05$ como nível de significância.

Os resultados revelaram presença de bactérias (coliformes a $45^{\circ} \mathrm{C}$ ou Salmonella) e/ou parasitas em 31 (69\%) das 45 cadeias de produção, sendo nas verduras no comércio em $16 \%$, no canteiro em $31 \%$ e após lavagem nos tanques em $22 \%$. A água de irrigação apresentou irregularidades em $22 \%$ e a água de lavagem de hortaliças em 38\% (Tabela 1). Apenas uma cadeia produtiva apresentou contaminação exclusivamente no ponto de venda, sem irregularidades no material colhido na horta. Por outro lado, 24 (54\%) cadeias de produção apresentaram contaminação em alguma amostra obtida na horta, mas não no comércio. A irregularidade mais freqüente foi a presença de elevada concentração de coliformes a $45^{\circ} \mathrm{C}$ em $10(22 \%)$ das amostras da água de irrigação, $11(24 \%)$ das verduras no canteiro, 15 (33\%) da água dos tanques de lavagem, $9(20 \%)$ das verduras após lavagem e 7 (16\%) das verduras no comércio. Constatamos ainda a presença de
Salmonella abaetetuba e de Salmonella sp nas hortaliças e de vários enteroparasitas considerados patogênicos ao homem tanto nas amostras de água como nas de verduras. As associações parasitárias observadas foram: Entamoeba sp e ancilostomídeos; Ascaris sp, Entamoeba sp e ancilostomídeos; Entamoeba sp e Giardia sp, Ascaris sp, Entamoeba sp e Isospora sp; Trichuris sp, Entamoeba sp e ancilostomídeos; Entamoeba sp, Isospora sp e ancilostomídeos. A detecção de Entamoeba sp e de ancilostomídeos, nem sempre patogênicos ao homem, foi valorizada somente em concomitância a um valor igual ou superior a $200 \mathrm{NMP} / \mathrm{g}$ de coliformes a $45^{\circ} \mathrm{C}$.

0 estudo comparativo ao longo do processo produtivo não revelou diferença estatisticamente significativa entre a água de irrigação e verdura no canteiro $(\mathrm{p}=0,29)$, entre esta e a água de lavagem $(\mathrm{p}=0,47)$, entre esta e a verdura póslavagem $(\mathrm{p}=0,11)$ e, finalmente, entre esta e a hortaliça no ponto de venda $(\mathrm{p}=0,56)$, não evidenciando, portanto, a existência de um risco cumulativo de contaminação nas sucessivas etapas da cadeia produtiva de hortaliças. Provavelmente, a maior frequiência de contaminação nos pontos de venda $a^{9}$ em relação às hortas ${ }^{8}$, observada anteriormente em nosso município, foi decorrente de outros fatores como procedência de hortaliças de outras localidades e variação sazonal ${ }^{7}$.

Apesar da relevância das doenças transmitidas por alimentos, a falta de estudos similares no Brasil impediu a comparação desses resultados com os da literatura.

0 presente estudo questiona a validade dos critérios de adequação qualitativa de hortaliças da legislação vigente, por desconsiderar coliformes a $45^{\circ} \mathrm{C}$. A pesquisa destas bactérias pode fornecer informações relevantes sobre a ocorrência de contaminação de origem fecal, assim como de outros agentes patogênicos, constituindo um indicador de condições sanitárias deficientes na produção de hortaliças.

Considerando os resultados obtidos neste estudo, ressaltamos a necessidade de vigilância sanitária mais atuante na fiscalização de todas as etapas do processo produtivo de hortaliças.

Tabela 1 - Resultado das análises microbiológica e parasitológica de 45 cadeias de produção de hortaliças no município de Ribeirão Preto, $\boldsymbol{S P}$.

\begin{tabular}{|c|c|c|c|c|c|}
\hline & \multicolumn{2}{|c|}{ Água } & \multicolumn{3}{|c|}{ Verduras } \\
\hline & irrigação nº & $\operatorname{tanque} \mathrm{n}^{0}$ & canteiro $\mathrm{n}^{\underline{0}}$ & pós-lavagem nº & comércio $n^{0}$ \\
\hline Coliformes* & 8 & 12 & 4 & 6 & 5 \\
\hline Salmonella abaetetuba & - & - & - & 1 & - \\
\hline Coliformes* + parasitas & 2 & 3 & 6 & 3 & 2 \\
\hline Coliformes* + Salmonella sp + parasitas & - & - & 1 & - & - \\
\hline Giardia sp & - & 2 & - & - & - \\
\hline Ascaris sp & - & - & 1 & - & - \\
\hline Associações parasitárias & - & - & 2 & - & - \\
\hline Total & $10(22 \%)$ & $17(38 \%)$ & $14(31 \%)$ & $10(22 \%)$ & $7(16 \%)$ \\
\hline
\end{tabular}

*coliformes a $45^{\circ} \mathrm{C}$ 


\section{REFERÊNCIAS BIBLIOGRÁFICAS}

1. Agência Nacional de Vigilância Sanitária. Diário Oficial da União, Ministério da Saúde. Resolução RDC n. 12, 02 de Janeiro de 2001, Seção 1, p.45-53, 2001.

2. American Public Health Association. Standard methods for the examination of water and wastewater. $19^{\text {th }}$ edition, American Public Health Association, Washington, p. 44- 50, 1995.

3. American Public Health Association. Technical Committee on Microbiological Methods for Foods. In: Downes FP, Ito K (eds) Compendium of methods for the microbiological examination of foods. $4^{\text {th }}$ edition, American Public Health Association, Washington, p. 357-380, 2001 .

4. Centers for Disease Control and Prevention. Diagnosis and management of foodborne illnesses: a primer for physicians. Morbidity and Mortality Weekly Report 50 (RR-2):1-69, 2001.
5. Centro de Vigilância Sanitária. Portaria n. 21 de 19 de Dezembro de 1991. Diário Oficial do Estado, São Paulo, 24 de Dezembro de 1991.

6. Dias RMTS, Mangini ACS, Torres DMAGV, Corrêa MOA, Lupetti N, Corrêa FMA, Chieffi PP. Cryptosporidiosis among patients with acquired immunodeficiency syndrome (AIDS) in the county of São Paulo, Brazil. Revista do Instituto de Medicina Tropical de São Paulo 30: 310-312, 1998.

7. Marzochi MCA. Estudo epidemiológico da poluição por enteroparasitas em áreas de horticultura da cidade de Ribeirão Preto, SP, Brasil. Tese de Doutorado, Universidade Estadual de Londrina, Londrina, PR, 1974.

8. Takayanagui OM, Febrônio LH, Bergamini AM, Okino MH, Castro e Silva AA, Santiago R, Capuano DM, Oliveira MA, Takayanagui AMM. Fiscalização de hortas produtoras de verduras no município de Ribeirão Preto, SP. Revista da Sociedade Brasileira de Medicina Tropical 33:169-174, 2000.

9. Takayanagui OM, Oliveira CD, Bergamini AMM, Capuano DM, Okino MHT, Febrônio LHP, Castro e Silva AAMC, Oliveira MA, Ribeiro EGA, Takayanagui AMM. Fiscalização de verduras comercializadas no município de Ribeirão Preto, SP. Revista da Sociedade Brasileira de Medicina Tropical 34:37-41, 2001. 